\title{
Impact of the COVID-19 pandemic on mothers: the social - psychological consequences and the need for counselling interventions
}

\author{
Samudra Senarath \\ Department of Educational Psychology, Faculty of Education, University of Colombo
}

\begin{abstract}
The World Health Organization declared the outbreak of the novel coronavirus disease (COVID-19) as a public health emergency of international concern in 2019. This study focuses on the impact of coronavirus on women who are mothers, in Sri Lanka. The objectives of the study were to identify the psychological and social effects experienced by mothers during periods of lockdown and to evaluate their life experience in the current context. The study sample consisted of 340 mothers from different geographical areas. They were categorized as Working and House Mothers. The questionnaire consisted of three sections: demographic information, the Health Cube SurveyCoronavirus 2019 (Stueck 2020) and a self-developed questionnaire about social relationships and related problems. The results of the study showed that Coronavirus has lifethreatening implications which have an overall negative impact on the mothers' psychological wellbeing and social life. Both groups of mothers had negative experiences during the lockdown period, and they reported difficult and different experiences. The Working Mothers reported more difficulties than the House Mothers, since they had to undertake several different roles/tasks in the home during lockdown, such as childcare, working from home and online learning/teaching while dealing with turmoil within the family. Both groups reported significant feelings of helplessness, emotional pain and anxiety about the safety of the family. They also experienced feelings of loss with regard to their social relationships and family members, together with feelings of isolation. Both groups of mothers reported significant changes in their lives, including negative emotions of meaninglessness, insecurity, confusion and sadness. However, the House Mothers reported more negative life evaluations than the Working Mothers. They also reported a significant increase in domestic violence during the lockdown period, as compared to the past. Therefore, persons who fall ill with coronavirus and quarantine persons should have access to online counselling and awareness programs to enhance their social and emotional wellbeing and to improve their quality of life. The government and the private sector should invest in resources relating the professionals to offer online or mobile telephone counselling for patients suffering from coronavirus as well as for persons quarantined at home, in order to improve their social and psychological wellbeing.
\end{abstract}

Keywords: Covid-19, psychological and social effects, mothers, counselling interventions, wellbeing

\section{INTRODUCTION}

$\mathrm{T}$ he novel coronavirus disease of 2019 (“COVID-19") was first identified in December 2019 in Wuhan, capital of the
Hubei Province in China. Since then, the outbreak has expanded across borders, leading the World Health Organization (WHO) to declare COVID-19 a pandemic, on 11 March 2020. (WHO, 2020). As the global number of cases increased, the epicenter for the disease shifted from the Wuhan region in China to Europe and later to the United States and other countries. Governments across the world have resorted to varying levels of public health measures, including movement restrictions, nationwide curfews, travel bans and border closures to tackle the pandemic, even as the outbreak continues to spread. These measures are having a huge impact on people's lives. At this point, some form of lockdown has been imposed on one third of the world's population, involving approximately 2.6 billion people (Chaudhury \& Samudra, 2020). Apart from small nations like Singapore, European countries have attempted a complete nationwide lockdown, leading some to describe it as "the largest psychological experiment ever conducted." Surprisingly, China at the height of the pandemic, placed only about 760 million people under lockdown (van Hoof, 2020).

Sri Lanka recorded its first case of COVID-19 in a Chinese woman on $25^{\text {th }}$ January 2020 and the first Sri Lankan patient was recorded on 11th March, 2020. Schools were then closed and from 11th March to July 2020, the country was under an island-wide curfew. Social distancing was enforced as a proactive measure because Sri Lanka's healthcare sector has a limited capacity which could struggle in the event of a large outbreak. Sri Lanka initially imposed a lockdown and a period where citizens worked from home, to maintain at least $70 \%$ social distancing as advised by health experts. This however, did not materialize as expected since it did not effectively help in social distancing. As a result, an island wide intermittent curfew was introduced, while a few areas were identified as high risk, prompting an indefinite curfew for more than a month in an attempt to avoid the community spread of the virus.

In 2017 the Department of Census and Statistics published information to the effect that women spend $86.4 \%$ of their time performing unpaid domestic services for their household and family members, whereas men spend only $54 \%$ of their time on the same work (DCS, 2017). Families and children are particularly vulnerable during the virus outbreak with negative effects on their physical and psychological wellbeing 
(Brooks et. al., 2020) Some families have had to completely rearrange the management of their children, due to school closures while mothers who continue to work from home have had to struggle to maintain a balance between the demands of work and family, presumably accounting for the highest level of psychological distress (Brooks et. al.,(2020) ; Di Giorgio,et., al. (2020); Felix, Hasson, \& Giancario (2020). Mothers undertake the critical responsibility of taking care of their families, along with their duties at the workplace. Inevitably, they face specific challenges and imbalances while juggling the responsibilities of work and family life (Snow et. al., (2003). Studies show that the mother's responsibility for taking care of her children is, in many cases, a cause of anxiety. Working mothers worry about coping with their multiple roles of mother-wife-employee (Kline \& Snow, (1994); Meleis \& Stevens, (1992); Snow et al. (2003). Another study showed that the mother's multiple daily roles caused stress, guilt and dissatisfaction with their performance, both within their family and at work (Noor, 1999). The problem of this study was to measure the impact that coronavirus has had on the lives of mothers. The objective of the study was to identify the social and psychological effects on mothers who had to quarantine at home (lockdown) and to evaluate their life in the current context.

\section{LITERATURE REVIEW}

\section{Lockdown-the social and psychological effects}

The COVID-19 pandemic produced astonishing challenges and disruptions to peoples' daily lives and many have experienced overpowering feelings of doom and desperation. According to Murphy's (2020) study, during lockdown people experience five stages of emotional reaction, including disbelief, anger, sadness, acceptance and hope. These are strikingly similar to the stages of grief because both are connected to a profound sense of loss. It must be emphasized however, that reactions to a crisis vary. Some people will experience no symptoms, a few will experience extreme reactions while the majority are in-between. Furthermore, people do not experience emotions in any sort of linear order and may even move back and forth between the stages (Murphy, 2020). As a result of the pandemic, there have been complete lockdowns and human lives have suddenly been turned upside down. Newspapers are missing, people cannot go for a walk, eat out or even go to market and many social relationships are lost. Faced with these momentous changes, the first psychological reaction of most people is disbelief (How can these things happen to us?). Adjusting to this totally new reality is painful for all and extremely painful for some. During this period of crisis, everyone will suffer low periods of sadness, even resulting in tears. Quarantine is associated with higher stress levels, irritability, depression, insomnia, acute stress and trauma related disorders (Brooks, et al, 2020).

A Chinese study reported with 1210 sample the prevalence of $30 \%$ anxiety and 17 Depression respectively (Wang et al,
2020). Qiu et. al (2020) study with Chinese over 50,000 people reported a $35 \%$ prevalence of Post-traumatic stress and significantly higher psychological distress was seen in women and young adults. An internet based survey of 18,147 Italian respondents revealed that the prevalence, depression, anxiety, insomnia, high perceived stress and adjustment disorder was at $17.3 \%, 20.8 \%, 7.3 \%, 21.8 \%$, and $22.9 \%$, respectively. (Rossi et al., 2020).Regarding the current situation, researchers have observed that stress levels may increase during an epidemic, as people may fear for their health as well as the health of family members and friends, among other problems. This frequently results in difficulties in concentration, changes in sleeping patterns and changes in eating habits (WHO, 2020). Further, WHO (2020) reported that stress levels have risen sharply in the population together with rising rates of loneliness, depression, substance abuse, self-harm and suicidal ideation. Another study showed that older mothers have maintained healthier lifestyles than younger mothers, during the lockdown periods (Hadjicharalambous, et al., 2020). Mothers who lived in rural areas presented significantly greater well-being than mothers living in urban areas, because their family networks were more supportive. Mothers whose working conditions were good significantly more satisfied with their social relationships (Hadjicharalambous, et al., 2020). Studies showed that due to pandemic situation family relationships were disrupted. Children's difficulties with self-regulation had a negative impact on mothers. (Brooks, et.al (2020); Liu, Bao, Huang, Shi, Lu, (2020).

\subsection{Counselling and Telephone Counselling Intervention}

Counselling is the process of helping people to understand and clarify their views and to learn to reach their self-determined goals through meaningful, well-informed choices and through the resolution of problems that could be of emotional or interpersonal nature (Corsini and Wedding, (2008). It is a relationship in which a trained and experienced professional person (the counsellor) provides information to a counselee (a troubled person) which the latter uses to overcome his challenges and problems. The goal of counselling is to help the counselee find solutions to whatever problems he finds around him. The British Association for Counselling and Psychotherapy (2013) defines counselling as a service delivered by trained counsellors or practitioners who work with people over a short or long term to help them bring about effective change or enhanced wellbeing. Counselling could also be explained as a number of procedures used in assisting an individual in solving problems which arise in various aspects of a client's life or in assisting him to minimize his overall personal development issues. Counselling is a professional service which aims to help people adjust to their environment, acquire problem-solving skills, manage their lives effectively and live meaningfully to achieve potentialities and psychosocial wellbeing. Counsellors provide services in a variety of settings and to diverse individuals with many different challenges. Combining a counselling approach 
with techniques and skills that involve emotional support, recognizing a client's strengths and listening to him review his life story, helps the individual to come to a better acceptance of his health and he is able to lead a new and meaningful life despite the condition. Counselling support helps a suffering patient free himself from all forms of tension and negative feelings, to express his fear, anxiety and sorrow and give rise to hope. It stimulates the patient to fight actively, replacing passivity, helplessness and resignation (Effiong, et al, 2020). It gives the suffering person the strength to fight for survival by building positivity. Coronavirus brings many pressures on people's lifestyles and results in debilitating and lifethreatening complications which overall have a negative impact on a patient's wellbeing and social life. The stresses and demands of living with coronavirus affect interpersonal and social relationships. Thus Counselling for corona virus patients include approaches such as emotional support, group counselling, counseling, counselling for self-care, sexual health counselling, family counselling, lifestyle counselling and counselling for the aged (Effiong, et al, 2020). Corona virus can bring up unresolved concerns for an individual, so counsellors are becoming a significant member of the interdisciplinary health team and are helping to make positive contribution to patients' quality of life. In general, telephone therapy was found appropriate in reducing the mental health burden of COVID-19 (Liu et al., (2020); Zhou et al., (2020). According to Pierce, Perrin, and McDonald (2020), those who were more likely to use tele-therapy prior to COVID-19 practiced in Veterans Affairs Medical Centers or within an individual or group practice. Castro et al (2020) found that telephone-delivered psychotherapy may be an effective strategy to reduce depression symptoms and shows adequate treatment adherence. Barak and Grohol (2011) reviewed and summarized the research in 2011 for online mental health interventions and found that there was strong evidence to support the effective use and future development of a variety of online mental health applications. Hence, telephone counselling viable to implement for persons suffering from coronavirus, to enhance their social and psychological wellbeing, and improve their quality of life.

\section{METHOD}

\subsection{Sample and data collection}

The sample in this study consisted of 340 mothers from different geographical areas. A total of 366 respondents began the survey and the final collection was 340 . The majority of the mothers $(69 \%)$ belonged to the age group of $40-56$ years and the others $(31 \%)$ were $30-39$ years in age. The majority $(92 \%)$ of the mothers were married and only $8 \%$ were single mothers. $66 \%$ had two children in the family, $21 \%$ had three children and $13 \%$ had one child in the family. The survey took place online in June 2020 and focused on working and housemothers. 69\% (or 236) working mothers and $31 \%$ (or 104) house-mothers participated in the study. Of the working mothers, a majority of $66 \%$ were teachers, $12 \%$ were university lecturers and $22 \%$ represented other services.

Instruments: The questionnaires consisted of three subsections. Section one was demographic information, age, marital status, family and career status. Section two was the psychological health questionnaire, specific for the Health Cube Survey-Corona virus 2019 (Stueck, 2020). The questionnaire was translated into "Sinhala language" by translators who were also psychologists. The questionnaire consists of several sub-scales including: the nature of life in the current situation, feelings and behaviorial changes during the COVID pandemic, a comparison with life before the present situation and describing the hardest situation with the outbreak. The third section was about social issues. The questions were self-developed and related to the nature of social relationships and interaction with family members and the nature of social isolation. The online survey took about 30 minutes to be completed. The study primarily used quantitative data analysis techniques, together with the statistical package SPSS 20 for Windows. Data analyses were done with descriptive statistics as mean, standard deviation, frequencies, percentages and chi-square.

\section{RESULTS AND DISCUSSION OF THE STUDY}

The mothers were asked the question: "How do you experience the current situation?" 68\% of the Working Mothers responded 'Difficult' while 32\% of the Working Mothers described "Different" experiences. Of the House Mothers, 86\% responded 'Difficult' and 14\% described "Different" experiences. Neither both groups responded 'Positive' to any aspect of the current situation. To the question: "What are you experiencing at home with your children? What is positive/ difficult/different?", $92 \%$ of the Working Mothers responded "Difficult" with their children and $56 \%$ of the House Mothers reported that it was difficult with children at home during the lockdown period. The Working Mothers stated that "They had to play different roles at home during the lockdown, such as childcare, work at home, family chaos etc." 
Table 1: Life and attitude changes in everyday life for mothers in the context of the coronavirus pandemic

\begin{tabular}{|c|c|c|c|c|c|c|c|c|c|c|c|c|}
\hline \multirow{4}{*}{$\begin{array}{l}\text { The coronavirus situation, life } \\
\text { and attitude change }\end{array}$} & \multicolumn{12}{|c|}{ Life changes } \\
\hline & \multicolumn{6}{|c|}{ Working Mothers } & \multicolumn{6}{|c|}{ House-Mothers } \\
\hline & \multicolumn{2}{|c|}{ Mild } & \multicolumn{2}{|c|}{ Moderate } & \multicolumn{2}{|c|}{ Severe } & \multicolumn{2}{|c|}{ Mild } & \multicolumn{2}{|c|}{ Moderate } & \multicolumn{2}{|c|}{ Severe } \\
\hline & $\mathrm{N}$ & $\%$ & $\mathrm{~N}$ & $\%$ & $\mathrm{~N}$ & $\%$ & $\mathrm{~N}$ & $\%$ & $\mathrm{~N}$ & $\%$ & $\mathrm{~N}$ & $\%$ \\
\hline $\begin{array}{c}\text { Do you feel that the } \\
\text { coronavirus situation is a } \\
\text { burden in your everyday life? }\end{array}$ & 54 & 23 & 108 & 46 & 74 & 31 & 24 & 23 & 45 & 43 & 35 & 34 \\
\hline $\begin{array}{l}\text { Do you experience the } \\
\text { situation regarding the } \\
\text { coronavirus as a threat? }\end{array}$ & 36 & 15 & 84 & 36 & 116 & 49 & 12 & 12 & 76 & 73 & 16 & 15 \\
\hline $\begin{array}{l}\text { To what extent have you been } \\
\text { able to completely relax in } \\
\text { calm moments? }\end{array}$ & 136 & 57 & 54 & 23 & 46 & 20 & 66 & 64 & 22 & 21 & 16 & 15 \\
\hline $\begin{array}{l}\text { Has your attitude changed } \\
\text { regarding where you want to } \\
\text { live? }\end{array}$ & 102 & 43 & 86 & 36 & 48 & 21 & 33 & 32 & 41 & 39 & 30 & 29 \\
\hline $\begin{array}{c}\text { What is the level of bother for } \\
\text { you in your day to day } \\
\text { activities in this situation? }\end{array}$ & 34 & 14 & 93 & 40 & 109 & 46 & 24 & 23 & 61 & 59 & 19 & 18 \\
\hline
\end{tabular}

Source: Research Data, 2020

The mothers were asked the question: "Do you feel that the coronavirus situation is a burden in your everyday life?" $23 \%$ of the Working Mothers responded 'Mild', 46\% responded 'Moderate', and $31 \%$ responded 'Severe'. 23\% of the House Mothers responded 'Mild', 43\% responded 'Moderate' and $34 \%$ responded 'Severe' to the same question.

To the question: "Do you experience the situation regarding the coronavirus as a threat?", 15\% of the Working Mothers responded 'Mild', 36\% responded 'Moderate' and 49\% responded 'Severe', while $12 \%$ of the House Mothers responded 'Mild', 73\% responded 'Moderate' and 15\% responded 'Severe'. To the question: "To what extent have you been able to completely relax in calm moments?" $57 \%$ of the Working Mothers responded 'Mild' while 64\% of the House Mothers reported 'Mild,' this meant that the mothers were unable to relax, due to the lockdown. To the question: "Has your attitude changed regarding where you want to live?" $21 \%$ of the Working Mothers responded 'Severe' while 29\% House Mothers reported 'Severe'. When asked the open question: "Which place would you want to live?", a majority $78 \%$ of the sample members responded that "Rural areas were better places to live" and $22 \%$ responded that "Home is the ideal place to live". To the question: What is the level of bother for you in your day to day activities in this situation? $40 \%$ of the Working Mothers responded 'Moderate' and 46\% responded 'Severe' while 59\% of the House Mothers others reported 'Moderate' and 18\% responded 'Severe'.

Table 2: Mothers Feelings during the Lockdown

\begin{tabular}{|c|c|c|c|c|c|}
\hline $\begin{array}{l}\text { How did you feel during } \\
\text { the COVID-19 } \\
\text { lockdown period-last } \\
\text { month? }\end{array}$ & $\begin{array}{l}\text { Not } \\
\text { true } \\
(\%)\end{array}$ & $\begin{array}{l}\text { True } \\
(\%)\end{array}$ & $\begin{array}{l}\text { Completely } \\
\text { true }(\%)\end{array}$ & $\begin{array}{l}\text { Chi- } \\
\text { square } \\
\chi^{2}\end{array}$ & $\begin{array}{l}\mathrm{P} \\
\text { value }\end{array}$ \\
\hline I have felt helpless & 9 & 45 & 46 & 36.020 & .00 \\
\hline I have felt emotional & 15 & 35 & 50 & 42.213 & .00 \\
\hline
\end{tabular}

\begin{tabular}{|c|c|c|c|c|c|}
\hline pain & & & & & \\
\hline $\begin{array}{l}\text { I have been frustrated } \\
\text { that I could not do more }\end{array}$ & 21 & 57 & 22 & 27.903 & .00 \\
\hline $\begin{array}{l}\text { I have been afraid for } \\
\text { my safety }\end{array}$ & 10 & 69 & 21 & 36.173 & .00 \\
\hline $\begin{array}{l}\text { I have felt guilty that not } \\
\text { enough was being done }\end{array}$ & 49 & 39 & 12 & 3.587 & .14 \\
\hline $\begin{array}{l}\text { I have been ashamed of } \\
\text { my emotional reaction }\end{array}$ & 33 & 41 & 26 & 12.648 & .03 \\
\hline $\begin{array}{l}\text { I have been worried } \\
\text { about family safety }\end{array}$ & 12 & 62 & 26 & 29.361 & .00 \\
\hline I have felt isolated & 41 & 20 & 39 & 44.851 & .00 \\
\hline $\begin{array}{l}\text { I have felt lost my all } \\
\text { relationships }\end{array}$ & 15 & 56 & 29 & 46.359 & .00 \\
\hline $\begin{array}{l}\text { I have felt other } \\
\text { people's moods affect } \\
\text { me }\end{array}$ & 24 & 46 & 30 & 47.189 & .00 \\
\hline
\end{tabular}

Source: Research Data, 2020

Regarding the mothers' feelings during the lockdown: Responding to the statement "I have felt helpless", $45 \%$ of the Working Mothers responded 'True', 46\% responded 'Completely true', while 9\% responded 'Not true' $(\chi 2=$ $36.020, \mathrm{p}<.001)$. Regarding the statement about emotional pain: 35\% responded 'True' and 50\% responded 'Completely true', but $15 \%$ said 'Not true' $(\chi 2=42.213 \mathrm{p}<.001)$. To the statement "I have been afraid for my safety", $69 \%$ responded 'True', 21\% responded 'Completely true' while 10\% responded 'Not true' $(\chi 2=36.173 \mathrm{p}<.001)$. The mothers also significantly showed that they have worries about their family's safety as well $(\chi 2=29.361 \mathrm{p}<.001)$.

The mothers also responded to the statement: "I have felt other people's moods affect me". 46\% responded 'True' and $30 \%$ responded 'Completely true', while $24 \%$ responded 'Not true' $(\chi 2=47.189 \mathrm{p}<.001)$. To the statement: "I have felt lost my all relationships", 56\% responded 'True', 29\% responded 'Completely true", while $15 \%$ responded 'Not true' $(\chi 2=$ 
$46.359 \mathrm{p}<.001)$. The mothers also reported significant feelings of isolation $(\chi 2=44.851, \mathrm{p}<.001)$ and I have felt guilty that not enough was being done" $(\chi 2=3.587, \mathrm{p}=.149)$. Thus the present study proved that the mothers' social relationships were significantly affected and they experienced feelings of isolation and other psychological effects. These findings are in line with studies conducted by Brooks et al., (2020); Snow et. al, (2020); Qiu et al,(2020)

Table: 3 Life Evaluation of both Groups in the context of the ongoing COVID-19 lockdown

\begin{tabular}{|c|c|c|c|c|c|}
\hline \multirow{2}{*}{ Life Evaluation } & \multicolumn{2}{|c|}{$\begin{array}{c}\text { Working } \\
\text { Mothers }\end{array}$} & \multicolumn{2}{c|}{$\begin{array}{c}\text { House } \\
\text { Mothers }\end{array}$} & \multirow{2}{*}{ P } \\
\cline { 2 - 5 } & Mean & SD & Mean & SD & \\
\hline $\begin{array}{c}\text { Sad/Meaningless- } \\
\text { meaningful }\end{array}$ & 7.26 & 1.23 & 10.6 & 2.12 & .00 \\
\hline Confusing-clear & 6.86 & 1.03 & 11.89 & 2.26 & .00 \\
\hline Frightening-fearless & 7.23 & 2.16 & 12.6 & 1.89 & .00 \\
\hline Emotionless-sensitive & 9.26 & 1.17 & 6.87 & .915 & .00 \\
\hline Aggressive-peaceful & 9.12 & 1.69 & 5.25 & 1.01 & .00 \\
\hline $\begin{array}{c}\text { Nervous-free of } \\
\text { complaints }\end{array}$ & 8.89 & 1.47 & 4.89 & 1.02 & .00 \\
\hline Irritable-patient & 5.89 & .714 & 7.26 & 2.21 & .02 \\
\hline Sad-Happy & 8.12 & 2.66 & 12.23 & 2.03 & .00 \\
\hline Tired-relaxed & 10.98 & 1.02 & 7.16 & 1.71 & .01 \\
\hline Insecure-self-confident & 6.25 & 1.41 & 13.79 & 2.89 & .00 \\
\hline
\end{tabular}

Source: Research Data, 2020

According to Table 3, with regard to the Life Evaluation of both Groups in the context of the ongoing COVID-19 lockdown: Feeling sad/meaningless-meaningful - WM $(\mathrm{M}=7.26 \mathrm{SD}=1.23)$, HM $(\mathrm{M}=10.6, \mathrm{SD}=2.12) \mathrm{p}<.001$. Feeling confused-clear WM $(\mathrm{M}=6.86 \mathrm{SD}=1.03), \mathrm{HM}(\mathrm{M}=11.89$, $\mathrm{SD}=2.26) \mathrm{p}<.001$. Feeling frightened-sensitive $\mathrm{WM}(\mathrm{M}=7.23$, $\mathrm{SD}=2.16)(\mathrm{M}=12.6, \mathrm{SD}=1.89) \mathrm{p}<.001$. Feeling insecure-selfconfident WM (M=6.25, $\mathrm{SD}=1.41), \mathrm{HM}$ (13.79, $\mathrm{SD}=2.89)$ $\mathrm{p}<.001$. Feeling sad- happy WM $(\mathrm{M}=8.12, \mathrm{SD}=2.66), \mathrm{HM}$ $(\mathrm{M}=12.23, \mathrm{SD}=2.03) \mathrm{p}<001$. These results were noted as the most prominent life-experiences for the two Groups, where the negative factors were significantly more evident for the Houses Mothers in contrast to the Working Mothers. Feeling Aggressive-peaceful WM (M=9.12, SD=1.69) HM (M=5.25, $\mathrm{SD}=1.01) \mathrm{p}<.001$. Feeling Nervous-free of complaints WM $(\mathrm{M}=8.89, \mathrm{SD}=1.47) \mathrm{HM}(\mathrm{M}=4.89, \mathrm{SD}=1.02) \mathrm{p}<.001$. Feeling Irritable-patient $\mathrm{WM}(\mathrm{M}=5.89, \mathrm{SD}=.714) \mathrm{HM}(\mathrm{M}=7.26, \mathrm{SD}=$ 2.21) $\mathrm{p}<.02$. These results relating to the Mothers' Life Evaluation indicate a certain level of negativity during the lockdown periods, although the House Mothers presented more mean scores than the Working Mothers. These findings are in line with previous studies by Di Giorgio, Di Riso, Mioni, et al., (2020); Liu, Bao, Huang, Shi ,Lu,(2020).

\subsection{Social and domestic trigger factors}

Domestic Violence: Following are the replies given to openended questions relating to social issues and social/domestic relationships, during the lockdown. The questions concerned the nature of the relationships between family members. One of the main issues that women face during a lockdown of this nature is domestic violence. There was an increase in the number of cases of domestic violence reported $(n=17,16 \%)$ in the families of the House Mothers' and for the Working Mothers $(n=12,5 \%)$, who have been in a prolonged violent relationship. Among them $(\mathrm{n}=5,2 \%)$ Working Mothers reported that "Work is seen as only escape and the window to find comfort is blocked at the moment due to the lockdown". They do not have the option of leaving home during the lockdown and sometimes cannot even go to their relatives' or parents' homes, which is a really big trigger factor of stress for them. The results showed that mothers in rural areas experienced a lower level of domestic violence than those in urban areas. Younger mothers reported being more victimized by domestic violence than older ones. These findings are in line with Hadjicharalambous, et al., (2020).

The Mothers' role: Child-Care, in the sample studied, the mothers stated that they "Needed more self-care time during the lockdown, as mothers and wives. Women are more burdened with cooking, cleaning and having to attend to their family members since they are all at home. They were forced to cook extra meals and snacks for their children and husbands. Some of the House Mothers were also worried about money issues."

The Mothers' role: Child Education, The mothers stated that there were also "Extra pressures on them, especially regarding their children's education. As there was no access to school or tuition, the mothers had to play a role in home-schooling in order to teach their children and ensure that they completed the tasks assigned by their teachers during this period." In answer to the question "Are you involved in getting online counselling? $(9 \%, 21)$ of the Working Mothers responded that they have discussed their family issues with counsellors through telephone counselling sessions and they received a certain level of coping skills through these sessions, while the rest of the mothers in the sample were not aware of the hotline for counselling services.

\subsection{Conclusion and suggestions}

Coronavirus has life-threatening implications which have an overall negative impact on the mothers' psychological wellbeing and social life. Both groups of mothers had negative experiences during the lockdown period, and they reported difficult and different experiences. Both groups reported a negative life evaluation. The mothers felt the loss of all their relationships, fear about losing family members to coronavirus and significantly, felt isolation. Incidents of domestic violence increased during the lockdown and the mothers had to play different roles while dealing with the chaos at home. The younger mothers were found to be more victimized than the older mothers.

Counselling should be made available to persons infected with coronavirus, in order to enhance their social wellbeing and to 
improve their emotional wellbeing and quality of life. Isolation centers should be set up with intercoms and online counselling so that patients in isolation can receive emotional support from family members and friends, during this period. The government and the private sector should organize and invest reasonable resources in online or telephone/mobile counselling for coronavirus patients and for people quarantining at home, in order to enhance their wellbeing. Individuals of all ages are encouraged to join online or telephone counselling sessions, to reduce the pain they suffer, through domestic violence, family disruption, relationship and marital problems, workplace issues, mental health concerns, personal issues and other concerns affecting their social and psychological wellbeing.

\section{REFERENCES}

[1] Barak, A., \& Grohol, J. M. (2011). Current and future trends in Internet-supported mental health interventions. Journal of Technology in Human Services, 29, 155-196. http://dx.doi.org/10.1080/ 15228835.2011.616939

[2] British Association for Counselling and Psychotherapy (2013)

[3] Brooks, S. K., Webster, R. K., Smith, L. E., Woodland, L., Wessely, S., Greenberg, N., \& Rubin, G. J. (2020). The psychological impact of quarantine and how to reduce it: Rapid review of the evidence. The Lancet, 395, 912-920.

[4] Castro, A., Gili, M., Ricci-Cabello, I., Roca, M., Gilbody, S., Perez-Ara, M. Á., McMillan, D. (2020). Effectiveness and adherence of telephone administered psychotherapy for depression: A systematic review and meta-analysis. Journal of Affective Disorders, 260, 514-526. http://dx.doi.org/ 10.1016/j.jad.2019.09.023

[5] Chaudhury, S. \& Samudra, M. (2020) Covid-19 Lockdown and Psychological Effects. Medical Journal of Dr. D.Y. Patil Vidyapeeth Vol. 13 Issue 6 November-December 2020

[6] Corsini, R. J., and Wedding, D. (2008). Current Psychotherapies. Belmont, CA: Thomson.

[7] Di Giorgio, E., Di Riso, D., Mioni, G. et al. The interplay between mothers' and children behavioral and psychological factors during COVID-19: an Italian study. European Child Adolescent Psychiatry (2020). https://doi.org/10.1007/s00787-020-01631-3

[8] Effiong,A.I., Nseobot, I.R., Simen, I.I.,Ette,U., Ahmed, M.S. et al.,(2020). Counselling for Covid-19 patients: Implications for scoail well-being. American Journal of Social and Humanitarian Research, Vol.1 No.3 p1-8

[9] Felix, I. A. M., Ilanit Hasson-O., \& Giancarlo, D. (2020). Psychological intervention and COVID19: What we know so far and what we can do. Psychological Interventions and the Covid-19 Pandemic, 1-21. DOI: $10.31234 /$ osf.io/8svfa

[10] Hadjicharalambous, D., Athanasiadi, D.C., Dimitrion, L. (2020) the Impact of the Covid-19 Social Isolation Measures on the Resilience and Quality of life of working Mothers. Social Education Research. Vol.2 Issue 1 p.41-51. http://ojis.wiserpub.com/index.php/SER.

[11] Kline, M., \& Snow, D. (1994). Effects of a worksite coping skills intervention on the stress, social support, and health outcomes of working mothers. Journal of Primary Prevention, 15(2), 105-121.

[12] Liu,J.J., Bao Y, Huang, X, Shi, J, Lu,L. (2020) Mental health consideration for children quarantined because of COVID-19. Lancet Child Adolescents Health 4 (5) p. 347-349. https://doi.org/10.1016/S2352-4642 (20)30096-1

[13] Liu, S., Yang, L., Zhang, C., Xiang, Y. T., Liu, Z., Hu, S., \& Zhang, B. (2020). Online mental health services in China during the COVID-19 outbreak. Lancet Psychiatry, 7(4), e17-e18. http://dx.doi .org/10.1016/S2215-0366(20)30077-8

[14] Meleis, A. I., \& Stevens, P. E. (1992). Women in clerical jobs: Spousal role satisfaction, stress, and coping. Women \& Health, $18(1), 23-40$.
[15] Murphy, A. (2020). The Five Emotional Stages of Lockdown and how to cope with each one in the Face of COVID-19-So which one are you in? Daily Mail Australia; 6 April, 2010. Retrieved on $5^{\text {th }} \quad$ December, 2020 from: https://www.dailymail.co.uk/femail/article-8190399/The-five emotional-stages-coronavirus-lockdown-impact-mental-health. html.

[16] Noor, N. (1999). Roles and women's well-being: Some preliminary findings from Malaysia. Sex Roles, 41(3-4), 123- 145

[17] Pierce, B. S., Perrin, P. B., \& McDonald, S. D. (2020). Demographic, organizational, and clinical practice predictors of U.S. psychologists' use of telepsychology. Professional Psychology: Research and Practice, 51, 184-193. http://dx.doi .org/10.1037/pro0000267

[18] Qiu J, Shen B, Zhao M, Wang Z, Xie B, Xu Y. A nationwide survey of psychological distress 332 among Chinese people in the COVID-19 epidemic: Implications and policy recommendations. Gen. Psychiatry 2020; 33:19-21.

[19] Rossi R, Socci V, Talevi D, Mensi S, Niolu C, Pacitti F, et al. (2020) COVID-19 pandemic and lockdown measures impact on mental health among the general population in Italy. An $\mathrm{N}=18147$ web-basedsurvey. [Doi: 10.1101/2020.04.09.20057802].: https://www.medrxiv.org/content/10.1101/2020.0

[20] Snow, D. L., Swan, S. C., Raghavan, C., Connell, C. M., \& Klein, I. (2003). The relationship of work stressors, coping and social support to psychological symptoms among female secretarial employees. Work \& Stress, 17(3), 241-263.

[21] Stueck, M. (2020) Health-Cube-Survey-Corona Virus COVID19. Network Bio centric Disaster and Health Management: DPFA

[22] Van Hoof, E. (2020) Lock Down is the World's Biggest Psychological Experiment and We will Pay the Price. World Economic Forum: 09 ,April,2020, Available from: from:https://www.weforum.org/agenda/2020/04/this-is-the-psycho logical-side-of-the-covid-19-pande mic-that-were-ignoring/..

[23] Wang C, Pan R, Wan X, Tan Y, Xu L, Ho C.S, et al. Immediate psychological responses and associated factors during the initial stage of the 2019 coronavirus disease (COVID-19) epidemic among the general population in China. International Journal Environment Research Public Health 2020; 17: pii: E1729. doi: 10.3390/ijerph17051729.

[24] World Health Organization (2020) WHO Director-General's statement on IHR Emergency Committee on Novel Coronavirus (2019-nCoV). WHO, Geneva

[25] Zhou, X., Snoswell, C. L., Harding, L. E., Bambling, M., Edirippulige, S., Bai, X., \& Smith, A. C. (2020). The role of telehealth in reducing the mental health burden from COVID-19. Telemedicine Journal and e-Health, 26, 377-379. http://dx.doi .org/10.1089/tmj.2020.006 